\title{
Los setenta años de la OEA
}

\author{
Jean-Michel Arrighi*
}

\section{RESUMEN}

En 2018, la OEA celebra los setenta años de su creación. Luego de una breve presentación sobre la evolución de su Carta fundacional de 1948 y del sistema interamericano desde sus inicios a fines del siglo XIX hasta el ingreso de los últimos miembros de la OEA en 1991, el presente artículo hace un recuento sucinto de los éxitos alcanzados por la Organización a lo largo de su existencia, destacándose el logro de una relativa paz entre sus Estados miembros proporcionada por la construcción de un tejido normativo e institucional interamericano basado en los principios fundamentales de igualdad jurídica de los Estados, no intervención, respeto al derecho internacional y solución pacífica de las controversias.

Posteriormente, se analizan la evolución de dichos principios en el transcurso de los setenta años de la Organización y los notables progresos obtenidos, principalmente en el desarrollo de un sistema regional de protección de los derechos humanos y para la defensa de la democracia representativa en el hemisferio. Finalmente, se destacan otros desarrollos jurídicos más recientes en el ámbito del derecho internacional privado, del acceso a la información, del combate a la corrupción, al crimen organizado y al tráfico de drogas, así como en materia de cooperación jurídica y judicial.

Al final se realiza un balance de los resultados conseguidos por la OEA vis-à-vis el surgimiento de nuevos organismos subregionales, los cuáles no han logrado sustituirla como el espacio político, único en la región, de elaboración jurídica, de defensa de los derechos humanos y de la democracia, que abarca a todos sus países en un pie de igualdad.

Palabras clave: Organización de los Estados Americanos (OEA), organismos internacionales, organizaciones regionales, sistema interamericano, derecho interamericano, panamericanismo, derechos humanos, democracia.

* Secretario de Asuntos Jurídicos de la OEA. Miembro del Institut de Droit International. Correo electrónico: jarrighi@oas.org 


\section{The OAS at Seventy Years}

\section{Abstract}

In 2018, the OAS celebrates seventy years of its creation. After a brief presentation on the evolution of its founding Charter of 1948 and of the Inter-American System from its inception at the end of the 19th century until the entry of the last members of the OAS in 1991, this article gives a succinct account of the successes achieved by the Organization throughout its existence, highlighting the achievement of relative peace among its member states provided by the construction of an Inter-American normative and institutional fabric based on the fundamental principles of legal equality of States, non-intervention, respect for international law and peaceful settlement of disputes.

Subsequently, the article reviews the evolution of these principles during the seventy years of the Organization and the notable progress made, primarily in the development of a regional system for the protection of human rights and for the defense of representative democracy in the Hemisphere. Finally, the article highlights other more recent legal developments in the field of private international law, access to information, combating corruption, organized crime and drug trafficking, as well as legal and judicial cooperation.

In the end, the article provides a review of the results achieved by the OAS vis-à-vis the emergence of new subregional organizations. These new organizations have not managed to replace the OAS as the political space of legal elaboration, defense of rights human rights and democracy, unique in the region, which encompasses all of its member states on an equal footing.

Keywords: Organization of American States (OAS), international organizations, regional organizations, Inter-American System, Inter-American law, Pan Americanism, human rights, democracy.

El 30 de marzo de 1948 se inauguraba en Bogotá la Novena Conferencia Internacional Americana que aprobaría, un mes después, el 30 de abril, la Carta de la Organización de los Estados Americanos ${ }^{1}$. Era esta la primera conferencia de la serie iniciada en 1889 que se realizaba luego del fin de la Segunda Guerra Mundial y de la creación de las Naciones Unidas ${ }^{2}$ en cuya carta constitutiva se preveía, a instancia de los países americanos, la existencia de acuerdos regionales para entender del mantenimiento de la paz y seguridad internacionales así como para la promoción del arreglo pacífico de controversias regionales y, llegado el caso, la aplicación de medidas coercitivas bajo

\footnotetext{
1 En esa misma conferencia se adoptaron, además, entre otros importantes textos, el Tratado Americano de Soluciones Pacíficas («Pacto de Bogotá), tratado que tuvo que esperar años para ser hoy la principal vía para resolver conflictos regionales ante la Corte de la Haya, y la Declaración Americana de los Derechos y Deberes del Hombre, documento pionero, anterior a la Declaración Universal. Se aprobaron allí el Convenio Económico de Bogotá y la Carta Internacional Americana de Garantías Sociales, los que nunca entraron en vigor.

2 La Octava Conferencia tuvo lugar en Lima, en 1938.
} 
la autoridad del Consejo de Seguridad ${ }^{3}$. Era tiempo entonces de fortalecer la Unión Panamericana creada a los inicios del proceso de las reuniones interamericanas para servirles de oficina de información y secretaría. Por ello se constituyó la organización regional ${ }^{4}$. La nueva organización quedó integrada con veintiún estados miembros, los países latinoamericanos, Haití y los Estados Unidos de América. Con el tiempo ingresarían nuevos miembros - los países del Caribe anglosajón y Canadá- hasta llegar a los treinta y cinco actuales. Sucesivas reformas a la Carta irían modificando su estructura, creando nuevos órganos y ampliando sus competencias, para adaptarla a los cambios y nuevas prioridades de la región.

\section{Algunas aproximaciones}

El balance de estos setenta años, inseparables del patrimonio jurídico e institucional que venía de las décadas anteriores, no es cosa fácil en tan poco espacio. Muchas aproximaciones son posibles. Una primera sería recorrer la historia de los ataques repetidos a la Organización en los que se la acusara de los males de la región, de estar al servicio de los peores intereses, hasta llegar en algunos casos a las alabanzas por su defensa de la democracia y de los derechos humanos. Otra sería, más serena, analizar la evolución de sus instrumentos jurídicos y de los trabajos de sus distintos órganos. Otra, tal vez, podría consistir en la lectura en el tiempo de la evolución de los fines y propósitos para la cual fue creada, enumerados en su artículo 2, y revisar su cumplimiento. Otra, por último, podría surgir del estudio comparado de su interrelación con otras instituciones subregionales, regionales y universales que fueron surgiendo a lo largo de este período. Difícil optar por una u otra vía. Tratemos, entonces, en estas pocas páginas, de dar algunas pistas sobre todas ellas más para inquietar al lector que para saciar su curiosidad.

Debo aclarar desde ya que soy un convencido de la importancia y de la necesidad de contar con un sistema interamericano. Creo que ha dado sus logros, que ha sabido tejer una red de normas y de instituciones comunes que cubren buena parte de las relaciones entre países y que nos han permitido a lo largo de más de un siglo contar con una región que, a diferencia de todas las demás, no ha conocido, salvo excepción aislada, guerras entre naciones que han sembrado la destrucción y la muerte de millones de personas, que ha venido superando las terribles violaciones masivas a los derechos humanos fruto del terrorismo de Estado, que ha sido un espacio único para el diálogo y también para la confrontación. Es un espacio donde el principio

\footnotetext{
3 Véanse los artículos 52, 53 y 54 del capítulo VIII: Acuerdos Regionales, así como el artículo 51 relativo a la legítima defensa colectiva de la Carta de las Naciones Unidas.

4 Para un desarrollo histórico de este proceso: Arrighi, 2015a.
} 
de la igualdad jurídica, más allá de las desigualdades reales, abre la puerta al reconocimiento de los más pequeños por los más grandes; donde, con sus idas y venidas, el principio de no intervención ha prevalecido, y donde el desarrollo y el respeto al derecho internacional acordado en la región ha permitido la cooperación en temas antes excluidos de la competencia de la organización. Y con respecto a esto último alcanza con seńalar la protección de los derechos humanos o la defensa de la democracia representativa, hoy prioridades de su actuación.

Es cierto que falta mucho por hacer. Es cierto, también, que el tejido institucional regional no siempre actúa coordinadamente ${ }^{5}$. Es cierto que las instituciones nacionales son frágiles en muchos de nuestros países y que falta aún para que se consolide un verdadero estado democrático de derecho. Pero mucho se ha avanzado, y de nada sirve querer separar o dividir lo que es, nos guste o no, nuestro espacio común compartido. Tampoco es justo pedirle a una organización internacional con un presupuesto limitado, con competencias acordadas y con un sistema de decisiones que responde a la voluntad mayoritaria de los países americanos y no al capricho de alguno o de unos pocos, que pueda subsanar todas las carencias que se dan en el ámbito interno de sus miembros. Pero, repito, mucho se ha hecho, y mucho se puede hacer en el futuro.

\section{Las Cartas de la OEA}

Desde 1948 hasta la fecha, la Carta de la OEA ha sido reformada en varias ocasiones. La primera de ellas en 1967 («Protocolo de Buenos Aires») revisó completamente la estructura orgánica; instituyó a la Asamblea General como su órgano supremo; incorporó nuevos Consejos; modificó la Secretaría General. La segunda reforma («Protocolo de Cartagena de Indias» de 1985) junto con nuevos artículos en el capítulo sobre desarrollo económico, introdujo el mandato para la organización de promover y consolidar la democracia representativa (actual artículo 2b) así como la facultad del secretario general de «llevar a la atención de la Asamblea General o del Consejo Permanente cualquier asunto que, en su opinión, pudiese afectar la paz y la seguridad del Continente o el desarrollo de los Estados miembros» (actual segundo párrafo del artículo 110, anterior artículo 116) ${ }^{6}$. En 1992 se incorporó a la Carta de la OEA («Protocolo de Washington») el actual artículo 9 que prevé la posibilidad

\footnotetext{
5 No dejo de perder la esperanza que tal vez algún día las cumbres de jefes de Estado y de Gobierno de las Américas - la primera de las cuales fue en Miami en 1994 y la octava en Lima este año 2018 - puedan ser justamente la instancia de coordinación del sistema, distribuyendo tareas, funciones, mandatos y recursos entre las instituciones interamericanas para asegurar la debida coordinación entre ellas.

6 El Perú formuló la siguiente reserva con relación a esta reforma: «La Delegación del Perú declara, como reserva, que las facultades otorgadas al secretario general en el artículo 116 no podrán ser ejercidas para aquellos asuntos ya
} 
de suspender a un Estado miembro cuyo gobierno democráticamente constituido hubiese sido derrocado por la fuerza. Y, finalmente, un año después, se adoptó una nueva reforma (Protocolo de Managua) la que fusionó dos anteriores Consejos en uno solo, el Consejo Interamericano para el Desarrollo Integral.

A diferencia de lo que ocurre en otras organizaciones internacionales en las que una reforma a su instrumento constitutivo obliga a todos sus miembros, ya porque la decisión mayoritaria se impone a todos o ya porque solo entra en vigor una reforma si ella ha sido ratificada por todos, las reformas a la Carta de la OEA solo obligan a quienes las han ratificado, creando así un tejido de Estados obligados por distintas normas ${ }^{7}$. El asunto no ha generado hasta la fecha conflictos; declaraciones unilaterales han permitido el funcionamiento - $\mathrm{y}$ desaparición - de órganos, pero el problema podría darse en caso de aquellas normas que suponen nuevas competencias tanto de la Asamblea General como del Consejo Permanente o del secretario general, reconocidas por algunos pero no por otros miembros (Arrighi, 1998).

Mediante estas reformas, la organización ha ido incorporando a su texto constitutivo nuevos fines y propósitos. El más importante de ellos, al sacarlo así del ámbito exclusivamente interno, es el que tiene que ver con la defensa de la democracia representativa, en lo cual la Carta de la OEA ha sido pionera. Ya lo mencionaba el texto de 1948 pero la reforma de 1985 hizo de ello una obligación para todos los miembros y un objetivo esencial a ser perseguido por todos los órganos de la organización regional. A partir de entonces, su defensa no violenta más el principio de no intervención.

\section{Los miembros de la OEA}

La Primera Conferencia Americana, celebrada en Washington D.C. en 1889, contó con la participación de representantes de dieciocho gobiernos americanos, incluido el Perú. En la Novena Conferencia, que en 1948 adoptara la Carta de la OEA, estuvieron representados veintiún países. Posteriormente ingresaron catorce nuevos miembros. Los tres últimos fueron Canadá en 1990 y, en 1991, Belice y Guyana. Hoy la organización cuenta con treinta y cinco países miembros. Solo uno - Venezuelaha presentado, en estos setenta años, denuncia a la $\mathrm{Carta}^{8}$. Por su parte Cuba, que fuera suspendido del sistema interamericano - y no solo de la OEA- en 1962, no denunció la Carta aunque no se ha incorporado a las actividades de la OEA a pesar

\footnotetext{
resueltos por arreglos de las Partes, o por laudo arbitral, o por sentencia de un tribunal internacional, o que se hallen regidos por acuerdos o tratados vigentes".

7 El Perú es parte de todos los protocolos de reforma a la Carta de la OEA habiendo formulado únicamente reservas al de 1985 .

8 La denuncia fue presentada en abril de 2017 y de mantenerse surtiría efectos en abril de 2019.
} 
del levantamiento de esta suspensión por la Asamblea General en su sesión del año 2009.

Es entre fines de la década de 1970 y durante la década de 1980 que ingresaron estos nuevos Estados, antiguos territorios británicos u holandeses del Caribe o de América del Sur. Interesante constatar cómo es durante los tiempos en que el nombre de la organización era objeto de las peores críticas — «ministerio de las colonias», "que fea es la $\mathrm{OEA}$ — que solicitaron su ingreso un número importante de nuevos Estados. Y también es necesario tomar nota que el gobierno que sin duda más la atacó, el cubano, nunca se retiró de la organización?

Al tiempo de la creación de la OEA, sus veintiún miembros representaban un número importante de países en el seno de las Naciones Unidas, compuesta entonces de cincuenta y un estados. Dueños de un patrimonio jurídico e institucional muy rico elaborado en la primera mitad del siglo $\mathrm{XX}^{10}$, tuvieron una influencia mayor en la agenda universal, tanto en la creación de agencias de cooperación como en la elaboración de un marco jurídico común, en asuntos tales como el derecho del mar, el derecho de los tratados, criterios para la delimitación de fronteras, la prohibición del uso de la fuerza o los medios y mecanismos para la solución pacífica de las controversias (Barberis, 1992; Cançado Trindade, 2014). Hoy ello ha cambiado: si bien ya son treinta y cinco los miembros de la OEA, su peso numérico, por lo menos, ha disminuido frente a los doscientos miembros de las Naciones Unidas. Y ello, por supuesto, afecta la participación regional en las distintas instancias. Buen ejemplo de ello es la presencia latinoamericana en la Corte Internacional de Justicia, hoy reducida a solo un juez ${ }^{11}$.

El ingreso de estos catorce nuevos miembros ha tenido - $\mathrm{y}$ tiene- su impacto en la agenda, prioridades y actividades de la organización regional. Sin entrar en más detalles, alcanza con constatar que anteriormente, cuando eran veintiuno los miembros, solo uno de ellos (los Estados Unidos de América) representaba un sistema jurídico

\footnotetext{
9 Así como tampoco denunció el Tratado Interamericano de Asistencia Recíproca (TIAR) de 1947, en virtud del cual se le impusieron las sanciones en 1962. Otros países, en cambio, sí lo denunciaron.

10 Baste recordar el establecimiento en los primeros ańos del siglo veinte de instituciones como la Organización Panamericana de la Salud, el Instituto Interamericano del Niño, el Comité Jurídico Interamericano, la Comisión Interamericana de Mujeres, la Unión Panamericana, en la propuesta de un Banco de Desarrollo, en la adopción de convenciones sobre los más diversos asuntos de derecho internacional público y de un código de derecho internacional privado. Es decir, un tejido normativo e institucional que solo parcialmente conocía el continente europeo, con una diferencia: Europa salía de dos guerras mundiales en menos de treinta ańos mientras que el continente americano solo en 1932 supo de un conflicto bélico entre dos de sus países, en el Chaco.

11 Los otros dos jueces nacionales de países miembros de la OEA son de países de common law. El artículo 9 de su Estatuto pide que estén representados no las regiones geográficas, sino «los principales sistemas jurídicos del mundo».
} 
de common law, los otros veinte, el «derecho civil»" ${ }^{12}$. Ahora ya son quince los países de derecho anglosajón ${ }^{13}$, y siguen siendo veinte los de derecho continental europeo.

Ello no es un mero cambio cuantitativo. Las prioridades de estos nuevos Estados referidas al desarrollo, a la amenaza destructora y repetida año tras año de los desastres naturales se han venido a sumar a las ya existentes en la organización. Y, por supuesto se han reflejado en la elaboración del derecho común de las Américas. El desafío es pasar de un derecho latinoamericano a la elaboración de un derecho verdaderamente interamericano, que refleje las distintas instituciones jurídicas, los distintos sistemas judiciales, las técnicas legislativas más adecuadas y hasta las dificultades que plantea, de ahora en más, la negociación en dos o más idiomas ${ }^{14}$. Ello, sumado a las dificultades de tiempo para su ratificación, ha llevado al mayor empleo de la técnica de la aprobación de leyes-modelo, guías para las legislaciones nacionales, más que a la adopción de convenciones o tratados interamericanos. Ha sido, para solo citar dos ejemplos, el caso de la ley-modelo sobre acceso a la información pública o la ley-modelo sobre garantías mobiliarias. De esta forma se permite modernizar las legislaciones nacionales, asemejarlas unas a otras, respetando las técnicas legislativas internas. Por otra parte, dada la rápida evolución de la tecnología, el creciente "comercio» entre naciones, la fuerte presencia y la necesidad del combate a las distintas modalidades del crimen organizado, es siempre más rápido y fácil adecuar y actualizar las normas internas que modificar acuerdos internacionales.

Junto a los Estados miembros de la Organización, tienen participación, presencia y contribuyen, los demás Estados de la comunidad internacional que, por no ser Estados americanos no pueden gozar de todos los derechos. Se les denomina en el ámbito de la OEA, Estados Observadores Permanentes. Desde 1971, año en que fuera creada esta categoría, a la fecha, son setenta los Estados extracontinentales que han solicitado ser incorporados. Algunos de ellos tienen, además, una misión exclusiva para atender los asuntos de la OEA ${ }^{15}$. Varios de ellos contribuyen financieramente, en forma significativa, con los programas y actividades de la organización, en particular aquellos referidos a la defensa de la democracia o a la protección de los derechos humanos.

\footnotetext{
12 Para un análisis sobre algunas implicancias de la "convivencia» de los dos sistemas jurídicos en las Américas, véase: Perret, 2001.

13 Canadá tiene los dos sistemas jurídicos, y dos idiomas oficiales en la redacción de su legislación.

14 Si bien la Carta de la OEA prevé que son idiomas oficiales el español, el inglés, el francés y el portugués y en los tratados interamericanos se les reconoce igual valor, hay que reconocer que en la mayoría de los casos estos habían sido negociados principalmente en español. Es válido para las normas en materia de derechos humanos como para las numerosas convenciones interamericanas de derecho internacional privado aprobadas en el marco de las Conferencias denominadas CIDIP.

15 Es actualmente el caso de España, Francia e Italia.
} 
Además de los Estados, tienen una presencia creciente las organizaciones de la sociedad civil, los empresarios, las instituciones académicas. Su actuación ante la Comisión Interamericana de Derechos Humanos, la presentación de informes ante el Mecanismo de Seguimiento de la Convención Interamericana contra la Corrupción, su presencia en las instancias de elaboración de normas interamericanas, son un aporte significativo en el conocimiento institucional, en la tramitación de casos y denuncias, en la preparación de informes sobre las situaciones nacionales y en la difusión de la normativa elaborada en el marco regional.

Por último, menciono, sin poder detallarlo más, el vínculo de la OEA con otras organizaciones internacionales. Por una parte, con las demás organizaciones interamericanas; algunas creadas antes mismo que la propia OEA, como el caso de la Organización Panamericana de la Salud o el Instituto Interamericano del Nińo, la Niña y los Adolescentes; otras creadas por la OEA, como el caso del Banco Interamericano de Desarrollo; otras universales como las Naciones Unidas ${ }^{16}$ y sus agencias (CEPAL y otras), y otras regionales, subregionales tanto de las Américas como de otros continentes. Es creciente el número de los acuerdos de cooperación celebrados así como el intercambio de asistencia e información entre la OEA y las demás organizaciones internacionales.

\section{Los principios fundamentales}

Varios son los principios que rigen la relación de los Estados miembros de la OEA entre sí: la igualdad jurídica de los Estados; el principio de no intervención; el respeto al derecho internacional. De ellos derivan algunos otros, como el de la condena al uso de la fuerza y el de la solución de las controversias por medios pacíficos, el del respeto a los derechos humanos y el de la defensa de la democracia representativa.

Pero veamos algo de la evolución que han tenido todos ellos en el transcurso de estos setenta años.

Los tres primeros están íntimamente relacionados. Entre otros, el artículo 10 de la Carta de la OEA nos dice que «los Estados son jurídicamente iguales, disfrutan de iguales derechos e igual capacidad para ejercerlos [...]» y el artículo 11 que «todo Estado americano tiene el deber de respetar los derechos de que disfrutan los demás Estados de acuerdo con el derecho internacional».

\footnotetext{
16 La Carta de la OEA señala en su artículo primero que «dentro de las Naciones Unidas, la Organización de los Estados Americanos constituye un organismo regional», es decir con que lo es con relación a «los asuntos relativos al mantenimiento de la paz y la seguridad internacionales» (artículo 52 de la Carta de las Naciones Unidas).
} 
La igualdad jurídica de los Estados tiene consecuencias prácticas en el funcionamiento de la organización, en su proceso decisorio, y por lo tanto en la conformación de sus prioridades, de su agenda, de sus programas y actividades, de su presupuesto. En la estructura orgánica de la OEA hay instancias donde están representados los gobiernos de los Estados miembros, Asamblea General, la Reunión de Consulta de Ministros de Relaciones Exteriores, el Consejo Permanente y el Consejo para el Desarrollo Integral, de las cuales la primera es el órgano supremo. En efecto, la Asamblea General es quien decide la acción y la política generales y quien elige a los miembros de los órganos no gubernamentales (secretario general, miembros del Comité Jurídico Interamericano y de la Comisión Interamericana de Derechos Humanos). Tanto en la Asamblea como en los demás órganos gubernamentales, rige la norma de que todos los Estados miembros tienen derecho de participar y que cada uno de ellos tiene un voto. En todos estos órganos las decisiones se toman por mayoría. En ningún caso hay órganos de participación restringida a solo un grupo de países, y en ningún caso hay derecho a veto otorgado a alguno o a algunos Estados en desmedro de los demás ${ }^{17}$.

El principio de no intervención es la otra cara del principio de la igualdad jurídica. Este último es una ficción jurídica; los países no son iguales, los hay ricos y pobres, grandes y pequeños, en la región - y en la OEA - coexisten los últimos con la superpotencia mundial. Pero es una ficción necesaria para un ordenamiento jurídico internacional justo y democrático. Sin embargo, deben fijarse límites a la acción del Estado, en particular de los más grandes, para asegurar su efectivo respeto. La violación de la igualdad de los Estados es la intervención. Dice el artículo 19 de la Carta OEA que «ningún Estado o grupo de Estados tiene derecho de intervenir, directa o indirectamente, y sea cual fuere el motivo en los asuntos internos o externos de cualquier otro». En cambio, no hay intervención cuando el asunto deja de ser de un Estado unilateral y exclusivamente para ser, como lo dicen el artículo 10 y el artículo 3 a), un asunto regulado por el derecho internacional ${ }^{18}$. Y es aquí donde ha habido notables progresos, tanto en el ámbito universal, como, sobre todo, en el desarrollo del derecho interamericano. Es bien conocido lo que ha ocurrido con la protección de los derechos humanos ${ }^{19}$. En particular más adelante veremos lo que ha ocurrido

\footnotetext{
17 También es bueno recordar que, además, todas las sesiones de estos órganos son públicas, salvo que se decida lo contrario. Las sesiones de la Asamblea General y del Consejo Permanente son transmitidas en directo a través de la página web de la OEA.

18 Es difícil hoy conocer de un tema regulado por el ordenamiento jurídico interno que no lo esté, también, por normas de derecho internacional, sean estas bilaterales, subregionales, regionales o universales. El ordenamiento jurídico internacional ha conocido en estas últimas décadas modificaciones sustanciales: ha ampliado el número y la naturaleza de sus sujetos, ha visto modificaciones a su sistema de fuentes y ha ampliado el ámbito de su competencia. 19 No nos es posible en este texto ir más allá en el desarrollo de este tema que cuenta con una gran bibliografía.
} 
en lo relativo a la forma de gobierno, asunto que aún hoy, en el ámbito universal, es un asunto interno, pero no así en nuestra región.

Otro gran pilar que rige las relaciones interamericanas ha sido desde los inicios del sistema en 1889 el de la solución pacífica de las controversias. Ello fue la razón central que estuvo en la convocatoria de la Primera Conferencia Internacional Americana, ha sido objeto de numerosos instrumentos jurídicos en la región, pionera con la creación de la Corte Centroamericana de 1907 a 1917 y con la propuesta de creación de una Corte Interamericana de Justicia, y con el desarrollo de mecanismos desarrollados en el «Pacto de Bogotá» y en la propia Carta de la OEA. Aunque poco valorado, el resultado — que seguramente tenga también otras razones — ha sido el del continente más pacífico en las relaciones interestatales a lo largo del siglo $\mathrm{XX}^{20}$. Es cierto que durante el período de la guerra fría fue el Tratado Interamericano de Asistencia Recíproca, y las decisiones que tomara la Reunión de Consulta de Ministros de Relaciones Exteriores, el mecanismo mal utilizado para resolver controversias entre países cuando no para intervenir indebidamente en asuntos internos ${ }^{21}$.

Ante las escasas ratificaciones y buscando otra vía para resolver controversias, la Asamblea General propugnó, a mediados de la década de 1980, una revisión del Tratado Americano de Soluciones Pacíficas («Pacto de Bogotá») aprobado junto con la Carta, hace setenta años ${ }^{22}$, y que no había sido invocado hasta entonces. Finalmente, las propuestas de reformas no fueron aprobadas ${ }^{23}$, pero el Pacto, contra las previsiones mayoritarias, comenzó a ser la vía para llevar muchos de los diferendos entre países americanos ante la Corte Internacional de Justicia ${ }^{24}$, reafirmando así la vocación de nuestros pueblos por la solución pacífica de nuestras diferencias.

Asimismo, la OEA viene teniendo una importante participación en facilitar una solución a la disputa territorial que opone a Belice y a Guatemala. A ambos países se les ha propuesto desde la Secretaría General que acepten recurrir a la Corte Internacional de Justicia, razón por la cual está en vías de celebrarse una consulta popular en cada uno de estos dos Estados para decidir si se acepta dicha propuesta.

\footnotetext{
20 Siempre pongo el siguiente ejemplo: si toman el mapa de las Américas entre 1889 y hoy verán pocos, si alguno, cambios. Si hacen a lo largo de ese mismo tiempo el mismo ejercicio con el mapa de Europa verán una sucesión impresionante de cambios, de Estados que han desaparecido, de imperios inexistentes ya, de países divididos o reunidos, y en cada uno de esos cambios, guerras y miles y miles de muertos. Nada de esto ha ocurrido en América. 21 Se hizo uso y abuso del artículo 6 del TIAR relativo a la «agresión que no fuera ataque armado [...] o cualquier otro hecho o situación que pueda poner en peligro la paz de América»

22 El Perú lo ratificó en 1967. Formuló entonces varias reservas que retiró en el año 2006.

23 A estas propuestas se opuso duramente Jiménez de Arechaga (1987, pp. 3-11).

24 Entre los cuales varios asuntos que enfrentaron separadamente a Nicaragua con Costa Rica, con Honduras, con Colombia, y a Chile con Perú en el caso de la delimitación marítima y con Bolivia en dos casos. Lamentablemente, como consecuencia del fallo de la Corte de 2012 en el asunto que opuso Colombia a Nicaragua en el diferendo territorial y marítimo, el primero de estos dos países denunció el Pacto.
} 


\section{La defensa de la democracia representativa}

El texto original de la Carta de la OEA de 1948 mencionaba la aspiración del «ejercicio efectivo de la democracia representativa» como forma de organización política de los Estados americanos ${ }^{25}$. A ella, por entonces, no hacía referencia ningún instrumento internacional. Se vivían tiempos donde, luego de siglos de olvido, la palabra «democracia» renacía con fuerza al punto de servir, con adjetivos diferentes, para definir a cualquier forma de gobierno. Es por ello que, en 1959, la Quinta Reunión de los Ministros de Relaciones Exteriores reunidos en Santiago de Chile aprobó una declaración en que definía los elementos esenciales de la democracia representativa ${ }^{26}$ y señalaba su relación con la protección de los derechos humanos ${ }^{27}$.

Vinieron luego tiempos difíciles en la región; tiempo de dictaduras y de guerras civiles. Habría que esperar los mediados de la década de 1980 para ver un continente donde la mayoría de sus Estados eran gobernados democráticamente como nunca antes había ocurrido. Ello permitió que, en1985, se incorporase a la Carta de la OEA el actual artículo 2 b) que le fija a la organización, como uno de sus propósitos esenciales, de el "promover y consolidar la democracia representativa dentro del respeto al principio de no intervención». Véase que se trata de un mandato para toda la organización, es decir para todos sus órganos, sean estos de integración gubernamental o no, es decir, sea la Asamblea General, el Consejo Permanente o la Secretaría General ${ }^{28}$, el Comité Jurídico Interamericano (2011) o la Comisión Interamericana de Derechos Humanos. En 1991, la Asamblea General aprobó la resolución 1080 por la que se dispuso que, en caso de interrupción abrupta o irregular del legítimo ejercicio del poder, la Asamblea General o una reunión ad hoc de Ministros de Relaciones Exteriores pueda adoptar «las decisiones que se estime apropiadas, conforme a la Carta y al derecho internacional». Ello fue lo que ocurrió cuando se dieron las situaciones en Haití (1991), en Perú (1992), en Guatemala (1993) y en Paraguay (1996 y 2000) (Arrighi, 2015b). Un año después, el Protocolo de Washington incorporó el artículo 9 de la Carta que permite la suspensión del Estado miembro donde dicha situación se produzca.

\footnotetext{
25 Tercer párrafo del Preámbulo y el entonces artículo $5 \mathrm{~d}$ ), actual $3 \mathrm{~d}$ ).

26 El imperio de la ley, la separación de poderes, elecciones libres, libertad de prensa y de expresión, entre otros. Es bueno recordar en tiempos donde parece resurgir en algunos gobernantes la idea de su reelección indefinida, que esta resolución ya señalaba que «la perpetuación en el poder, o el ejercicio de este sin plazo determinado y con manifiesto propósito de perpetuación, son incompatibles con el ejercicio efectivo de la democracia representativa» (OEA, 1984, p. 202).

27 Fue en dicha reunión que se creó la Comisión Interamericana de Derechos Humanos. Los elementos que se señalaron, entonces, son, entre otros, la separación de poderes, el imperio de la ley, elecciones libres, respeto a los derechos humanos, y la libertad de prensa.

28 Ello le permitió a la Secretaría General desarrollar sus actividades de observación electoral y la creación de una Unidad de Promoción de la Democracia, actual Secretaría para el Fortalecimiento de la Democracia.
} 
Luego de la crisis peruana del año 2000, el gobierno de ese país propuso, y le fue aceptada por la Cumbre de Jefes de Estado y de Gobierno reunida en Quebec en abril de 2001, la adopción por la OEA de una Carta Democrática Interamericana (CDI). Dicho documento, luego de un intenso proceso de negociación, fue aprobado por la Asamblea General, en una sesión extraordinaria que tuvo lugar en Lima, el 11 de setiembre de ese mismo ańo. Este nuevo instrumento — una resolución de la Asamblea General- prevé cuatro situaciones distintas: la primera es cuando el gobierno de un Estado miembro considera "que está en riesgo su proceso político institucional democrático o su legítimo ejercicio del poder» en cuyo caso puede solicitar la asistencia del secretario general o del Consejo Permanente (artículo 17 de la CDI); la segunda es cuando quien llama la atención sobre esta situación es el secretario general o el Consejo Permanente y el Estado dónde ello ocurre da su consentimiento para la asistencia de estos órganos (artículo 18) ${ }^{29}$; la tercera situación es cuando hay «una alteración del orden constitucional que afecte gravemente su orden democrático» ${ }^{30}$ ante lo cual el secretario general o cualquier otro Estado lleva el asunto al Consejo Permanente, pero el Estado afectado ni solicita ayuda ni presta su consentimiento para ello (artículo 20) ${ }^{31}$; y, por último, cuando se produce la ruptura del orden democrático, en cuyo caso corresponde se suspenda al Estado donde ocurre (artículo 21) ${ }^{32}$. En ninguna de estas circunstancias, la invocación de las normas de los distintos instrumentos interamericanos puede ser considerada como contraria al principio de no intervención. Se trata de normas internacionales acordadas por los Estados miembros de la OEA y por lo tanto han excluido la defensa del sistema democrático de los asuntos de la competencia exclusiva del Estado.

Desde la Secretaría General, la organización de misiones de observación electoral, hoy reconocidas en toda la región, han ayudado a garantizar elecciones libres y transparentes, en un continente donde hasta no hace mucho la regla era el fraude. Hoy ello es la excepción; y cuando ocurre son el blanco de denuncia, de conocimiento de la opinión pública y pudiendo, llegado el caso suponer una alteración grave del orden democrático con sus posibles sanciones.

Quedan sin embargo aún algunas lagunas: solo pueden actuar los gobiernos en el seno del Consejo Permanente o de la Asamblea General, solicitando ayuda o votándola, o

29 Estos han sido los casos de Venezuela (2002), Bolivia (2003, 2005 y 2008), Nicaragua (2004 y 2005), Perú (2004) y Ecuador (2005 y 2010)

30 Sobre este concepto se pronunció el Comité Jurídico Interamericano en agosto de 2009 en resolución CJI/ RES.159 (LXXXV-O/09): «Elementos esenciales y fundamentales de la democracia representativa y su vinculación con la acción colectiva en el marco de la Carta Democrática Interamericana».

31 En virtud de esta disposición, desde al año 2016 el secretario general ha venido presentando informes al Consejo Permanente sobre la alteración del orden democrático en Venezuela.

32 Es la situación que se produjo con relación a Honduras en el año 2009, suspendido hasta el año 2011. 
el secretario general llamando la atención de estos órganos. Pero "gobiernos», para el orden jurídico internacional, son solo los poderes ejecutivos que son quienes tienen la representación internacional del Estado. Cuando otro es el poder afectado, le es difícil el acceso al escenario internacional.

Ha habido notables progresos en la región. Veníamos de una larga historia en que los conflictos entre poderes del Estado se resolvían en muchos casos mediante un golpe militar, eliminando a ambos poderes. Fue el caso, en general, de lo que ocurrió entre 1900 y 1990 donde hubo cerca de ciento ochenta golpes de este tipo. Hoy ello parece haber cesado. Pero eso no significa que hemos logrado el equilibrio de poderes que asegure una estabilidad democrática en algunos de nuestros países. Hoy han sido, y son, varios los casos en los que el conflicto entre poderes se resuelve ya mediante el avasallamiento del poder Ejecutivo sobre el Legislativo ya mediante actos del legislativo tendientes a destituir al presidente, no siempre ajustados a derecho (Pérez-Liñán, 2007; Mainwaring y Pérez-Liñán, 2014), en cualquier caso, con el riesgo de la amenaza de una alteración del orden democrático. Pero se han hecho muchos progresos en la participación de la prensa en las denuncias de irregularidades de las autoridades públicas, en la mayor independencia de los jueces y fiscales en la investigación y juzgamiento combatiendo la impunidad que existiera anteriormente, en el fortalecimiento de la sociedad civil. Y no es menor tampoco lo que se viene haciendo desde las organizaciones internacionales en todo ello: en la defensa de los derechos humanos y en la constitución de mejores canales para la cooperación jurídica y judicial en el combate a la criminalidad organizada, fuente muchas veces de desestabilización política mediante el financiamiento de las campañas de candidatos o mediante el temor que infunden a la población.

\section{Algunos desarrollos jurídicos recientes}

Las necesidades de la cooperación en los más variados ámbitos han servido de impulso a nuevos desarrollos de los instrumentos jurídicos interamericanos, y a poner en marcha mecanismos de apoyo, seguimiento, verificación y promoción de su cumplimiento.

Veamos solo algunos ejemplos ${ }^{33}$.

\footnotetext{
33 A los que acá se detallan, y que no hay espacio para examinar, debe agregarse lo relativo a la regulación de las telecomunicaciones, las reuniones ministeriales de trabajo, de turismo y de educación, el trabajo de la Junta Interamericana de Defensa, los programas sobre migraciones, trata de personas, personas con discapacidad, la red de consumo y salud.
} 
a. El derecho internacional privado

Desde los orígenes del sistema interamericano se propició la elaboración de códigos de derecho internacional tanto público como privado. En 1928 se aprobó el Código Bustamante de derecho internacional privado, pero no logró extenderse a todo el continente, dividido entre este y los Tratados de Montevideo de finales del siglo XIX y de 1940. A partir de la década de 1970, en el seno de la OEA, los países optaron por la aprobación de convenios sobre distintos aspectos específicos, abandonando la idea de un código general. Se inició entonces el proceso de las Conferencias Interamericanas Especializadas, las denominadas CIDIP, hasta hoy siete de estas conferencias. De ellas surgieron numerosos tratados relativos a la cooperación jurídica y judicial, al comercio, a la contratación, a las relaciones de familia, a los aspectos procesales. Si bien en buena parte de su historia la técnica jurídica utilizada fue la tradicional del tratado, últimamente se optó por integrar también la elaboración de leyes-modelo, de guías y de directrices (Fernández Arroyo, 2003). Tal ha sido el caso de la Ley Modelo sobre Garantías Mobiliarias o la Carta de Porte para el transporte de mercaderías. En el caso de la protección internacional al consumidor, el debate para decidir el mejor método de legislar — ley o tratado — ha paralizado, hasta la fecha, el desarrollo normativo en el ámbito interamericano.

\section{b. El acceso a la información}

La opción por elaborar leyes-modelo como forma de uniformizar las legislaciones nacionales ha tenido aceptación no solo en materias propias del derecho internacional privado, sino también en otros campos. Ellas evitan el largo proceso de ratificación, permiten una más fácil adaptación a los distintos sistemas jurídicos que componen la región, facilitan el camino a su modificación ante nuevos desafíos. Tal ha sido el caso de la Ley Interamericana de Acceso a la Información Pública, aprobada por la Asamblea General de la OEA en 2010. Esta fue el fruto de un proceso que tuvo su inicio en un fallo de la Corte Interamericana de Derechos Humanos ${ }^{34}$, seguido de estudios por parte del Comité Jurídico Interamericano, por grupos de expertos, por la Secretaría de Asuntos Jurídicos y finalmente por el Consejo Permanente y la Asamblea General. Con posterioridad a su aprobación, la Secretaría General inició un vasto programa de difusión que permitió que su texto sirviese de base para la adopción y la actualización de las legislaciones nacionales en varios países de la región. Ahora ya se está trabajando en la actualización de la Ley-Modelo así como en la preparación de directrices sobre lo que algunos consideran la contracara de este derecho: la protección de los datos personales, en especial cuando estos están en posesión de empresas privadas.

34 Caso «Claude Reyes y otros vs. Chile», sentencia de 19 de setiembre de 2006. 


\section{c. El combate a la corrupción}

Cuando a mediados de la década de 1990 se planteó por parte de algunos países la necesidad de estudiar la posibilidad de contar con instrumentos interamericanos para la cooperación en el combate a la corrupción no pocos alzaron la voz para oponerse por tratarse de un asunto que consideraban exclusivamente interno, sobre el cual, además no existían instrumentos internacionales para su tratamiento. Sin embargo, fruto de un trabajo conjunto del Consejo Permanente y del Comité Jurídico Interamericano logró finalmente aprobarse, en 1996, la Convención Interamericana contra la corrupción (Lagos, 1999) ${ }^{35}$. Solo con posterioridad a su adopción, la OCDE, la Unión Europea y las Naciones Unidas tuvieron, a su vez, convenciones para el combate a la corrupción. En el año 2001 se creó el Mecanismo de Seguimiento para la implementación de la Convención (MESICIC), formado por representantes gubernamentales que evalúan la situación en los países, formulan recomendaciones, proponen normas y efectúan visitas in situ.

Fuera de este mecanismo, como una actividad de la Secretaría General de apoyo al fortalecimiento de los instrumentos legales y de la justicia en sus Estados miembros, se ha constituido, en Honduras, la Misión de Apoyo contra la Corrupción y la Impunidad (MACCIH).

d. Nuevos acuerdos para la protección de los derechos humanos

A la Declaración Americana de los Derechos y Deberes del Hombre de 1948 y a la Convención Americana sobre Derechos Humanos de 19696, le han seguido nuevos acuerdos. Los más importantes son: la Convención Interamericana para prevenir y sancionar la tortura $(1985)^{37}$, el Protocolo adicional a la Convención Americana sobre Derechos Humanos sobre derechos económicos, sociales y culturales de $1988^{38}$, el Protocolo sobre la abolición de la pena de muerte de $1990^{39}$, la Convención Interamericana para prevenir, sancionar y erradicar la violencia contra la mujer de $1994^{40}$, la Convención Interamericana sobre la desaparición forzada de personas de ese mismo año ${ }^{41}$, la Convención Interamericana para la eliminación de todas las formas de discriminación contra las personas con discapacidad de $1999^{42}$, en 2013 dos convenciones interamericanas una contra el racismo y la discriminación racial, la

\footnotetext{
35 Ratificada por el Perú en 1997.

36 Ratificada por el Perú en 1978. En 1981 reconoció la competencia de la Comisión y de la Corte; en 1999 retiró el reconocimiento de la competencia contenciosa de la Corte, y en 2001 volvió a reconocerla.

37 Ratificada por el Perú en 1991.

38 Ratificado por el Perú en 1995.

39 Del cual el Perú no es parte.

40 Ratificada por el Perú en 1996.

41 Ratificada por el Perú en 2002.

42 Ratificada por el Perú en 2001.
} 
otra más amplia, contra toda forma de discriminación e intolerancia ${ }^{43} \mathrm{y}$, finalmente, en 2015, la Convención Interamericana sobre la protección de los derechos humanos de las personas mayores ${ }^{44}$. A su vez se han fortalecido sus mecanismos e instituciones de seguimiento: la Comisión Interamericana de Derechos Humanos, la Comisión Interamericana de Mujeres ${ }^{45}$, y en lo que respecta a los países que son parte de la Convención Americana, la Corte Interamericana de Derechos Humanos.

e. El combate al crimen organizado y al tráfico de drogas

El crimen organizado en sus múltiples modalidades, el tráfico de drogas, la circulación ilícita de armas de fuego, el terrorismo son hoy amenazas crecientes que afectan a las poblaciones de todos nuestros países sin excepción, de Norte a Sur. La OEA no es ajena a su combate. En el año 2003 se aprobó la Declaración de México sobre seguridad en las Américas que amplió la tradicional concepción de la seguridad vinculada a ataques armados externos a una vasta gama de amenazas que afectan la vida cotidiana, algunas de las cuales ya venían siendo objeto de regulación por los órganos de la organización regional. Ya desde la década de 1970 se venía considerando el terrorismo en la región, aprobándose finalmente una convención general en $2002^{46}$ con lo que cobró nueva fuerza el Comité Interamericano contra el Terrorismo (CICTE) establecido unos años antes. Asimismo, la OEA coopera con los países miembros con programas para garantizar la seguridad de las instalaciones informáticas y portuarias contra la posibilidad de ataques terroristas.

En lo que hace a la circulación de armas de fuego, la Convención Interamericana contra la fabricación y el tráfico ilícitos de armas de fuego, municiones, explosivos y otros materiales relacionados, de $1997^{47}$, estableció instancias de cooperación entre las autoridades nacionales para controlarlo y evitarlo, y se creó un comité consultivo encargado del seguimiento.

Ya desde 1986, la Asamblea General de la OEA puso en marcha la Comisión Interamericana para el control del Abuso de Drogas (CICAD) la que reúne, al más alto nivel, a las autoridades competentes, desarrolla programas de capacitación, propone directrices y normas-modelo, formula recomendaciones a los gobiernos ${ }^{48} y$ desde 1999 cuenta con su Mecanismo de Evaluación Multilateral (MEM).

\footnotetext{
43 El Perú ha firmado ambas convenciones en 2016.

44 De la que el Perú no es parte.

45 En 2004, la Comisión Interamericana de Mujeres constituyó el Mecanismo de Seguimiento de la Convención sobre violencia contra la mujer (MESECVI), el cual evalúa el cumplimiento de las obligaciones allí establecidas.

46 Ratificada por el Perú en 2003.

47 Ratificada por el Perú en 1999.

48 Tal es el caso del Informe sobre el problema de las drogas en las Américas de 2013, a solicitud de la Cumbre de jefes de Estado y de Gobierno celebrada en Cartagena de Indias en 2012.
} 
Como consecuencia de enfrentamientos internos y de conflictos fronterizos varias fueron las zonas sembradas de minas antipersonales. El programa de desminado en funcionamiento desde 1992 ha liberado a la región de esta sangrienta presencia.

f. La cooperación jurídica y judicial

La necesidad creciente de una mayor cooperación en la aplicación de los tratados interamericanos, el fortalecimiento y capacitación de las autoridades a cargo de los procedimientos de intercambios de solicitudes provenientes de otros países, la importancia de un conocimiento mutuo llevó a la celebración periódica de Reuniones de Ministros de Justicia o de las autoridades con similares competencias (procuradores generales en algunos países), convocadas por la OEA. En ellas se han puesto en marcha una serie de mecanismos con esa finalidad: una red de intercambio en materia de extradición y asistencia mutua en materia penal, un programa de capacitación a jueces y fiscales en el combate a los delitos comunes cuando son cometidos mediante el uso de medios electrónicos y la creación del Centro de Estudio de Justicia de las Américas (CEJA) que brinda asistencia técnica a los países miembros de la OEA en sus procesos de reforma judicial.

También se han venido abriendo espacios de capacitación a jueces nacionales en la aplicación de normas internacionales. Ello es una necesidad creciente. Difícil hoy que un juez no tenga que aplicar ante las más variadas situaciones (civiles, comerciales, penales, procesales, laborales, de derechos humanos) normas internacionales junto con su derecho interno. Se han iniciado encuentros nacionales con jueces y fiscales para discutir esta problemática, así como talleres de capacitación para la aplicación por ellos de laudos arbitrales, recurso cada vez más frecuente en el comercio, pero el que debe ser sometido luego al control o a la ejecución por parte del poder judicial.

Iniciado en Nicaragua, y hoy extendido a toda Centro América, Paraguay y el norte de Argentina la OEA tiene el Programa de Facilitadores Judiciales. Estos son personas seleccionadas en las comunidades rurales para asistir en la resolución de conflictos entre vecinos, acercar a las partes y, en su defecto, apoyar la actuación de las autoridades judiciales o de otras autoridades policiales y administrativas. Particularmente importante en poblados apartados, situados lejos de juzgados, los facilitadores han permitido una baja sustantiva de la violencia en zonas rurales y una mayor confianza en el estado de derecho ${ }^{49}$. En el sentido de promover el conocimiento del derecho internacional son importantes los cursos, seminarios, talleres que se organizan desde los distintos órganos de

\footnotetext{
49 Los países que hoy cubre el programa son: Argentina, Costa Rica, El Salvador, Guatemala, Honduras, Nicaragua, Panamá y Paraguay. Hasta la fecha son más de 12000 los facilitadores designados los que han ya realizado más de 40000 mediaciones. Son cerca de seis millones de personas las que tienen acceso a estos facilitadores.
} 
la OEA. En particular es preciso destacar el Curso de Derecho Internacional que, desde el año 1974, se celebra anualmente en la ciudad de Río de Janeiro organizado conjuntamente por el Comité Jurídico Interamericano y la Secretaría General ${ }^{50}$.

\section{Apuntes finales}

En estas pocas páginas hemos intentado un balance de estos muchos ańos de la organización regional. Entre tanto han surgido numerosas organizaciones subregionales, las unas con el fin de lograr la integración económica, las otras con fines de concertación política. Ello es normal y ello es positivo. Pero ninguna puede sustituir ni el espacio que cubre la OEA cuyos miembros van de Canadá a Argentina y Chile pasando por el Caribe y que permite en un pie de igualdad la interacción - y el enfrentamiento- entre países de muy distinto poder, de diferentes ideologías, de variados sistemas jurídicos.

Si uno hace una encuesta, seguramente se encontrará con que la OEA o es poco conocida o es conocida para mal. Y acepto que ello era lo que me ocurría antes de ingresar a su área jurídica y antes de conocer el trabajo hecho en los campos acá reseñados. Hoy la democracia en la región no es lo mismo que en las décadas de 1960 y 1970; hoy la situación de los derechos humanos, tampoco es la misma; hoy las instituciones, sin ser perfectas, han mejorado; hoy, como antes, las controversias entre nuestras naciones se resuelven por medios pacíficos; hoy, tenemos un tejido normativo e institucional que facilita la cooperación en mejorar la solidaridad y en enfrentar males que nos azotan.

Hay, en la organización, múltiples espacios donde temas tan sensibles como el combate a la corrupción, el tráfico de drogas o de armas, la regulación de las telecomunicaciones o la elaboración de leyes-modelo para uniformizar nuestros ordenamientos jurídicos, son objeto de un tratamiento en el que participan conjuntamente todos los países miembros más allá de las diferencias tecnológicas o ideológicas.

Más de una vez se dice y repite que la "OEA es lo que los Estados quieren que sea». Ello no siempre es cierto: hay veces en que la OEA hace y dice cosas que los Estados no quieren que diga o haga, como ha sido en asuntos vinculados a la defensa de la democracia o a la denuncia de violaciones a los derechos humanos. Y hay veces en que la OEA es menos de lo que los Estados quieren que sea: alcanza con recorrer la lista infinita de mandatos y solicitudes de actividades que se le hacen y compararlas con el pobre presupuesto que se le aprueba para constatarlo.

\footnotetext{
50 Los cursos dictados son publicados en volúmenes anuales los que también pueden ser consultados electrónicamente en la página de la Secretaria de Asuntos Jurídicos de la Secretaría General. En el año 2000 la Secretaría General de la OEA publicó en forma temática, los cursos dictados sobre Derecho Internacional Privado y sobre Derecho Interamericano. Este curso está abierto a jóvenes juristas americanos y tiene actualmente una duración de tres semanas.
} 
Pero, en cualquier caso, en estos setenta años de vida, ha sido y es el espacio político, de elaboración jurídica, de defensa de los derechos humanos y de la democracia, único en la región, que abarca a todos sus países en un pie de igualdad.

\section{Referencias}

Arrighi, J.M. (1998). Les réformes à la Charte de l'Organisation des Etats Américains: problèmes de droit des traités. Annuaire Français de Droit International, 43.

Arrighi, J.M. (2015a). La OEA y el derecho internacional. Ciudad de México: Ed. Porrúa.

Arrighi, J.M. (2015b). The democracy clause in the Americas. En Les limites du droit internationallthe limits of international law: essays in honour of Joe Verhoeven. Bruselas: Ed. Bruylant.

Barberis, J. (1992). Les règles spécifiques du droit international en Amérique Latine. Recueil des Cours, 235.

Cançado Trindade, A.A. (2014). The contribution of Latin American legal doctrine to the progressive development of international law. Recueil des Cours, 376.

Comité Jurídico Interamericano. (2011). La democracia en los trabajos del Comité Jurídico Interamericano. Washington D.C.: Secretaría General de la OEA.

Fernández Arroyo, D. (2003). La CIDIP VI: cambio de paradigma en la codificación interamericana del derecho internacional privado. En Comité Jurídico Interamericano, XXIX Curso de Derecho Internacional - Rio de Janeiro 2002 (pp. 465-499). Washington D.C.: Secretaría General de la OEA.

Jiménez de Aréchaga, E. (1987). Tentativas de reforma del Pacto de Bogotá. En Anuario Jurídico Interamericano 1986 (pp. 3-11). Washington D.C.: Secretaría General de la OEA.

Lagos, E. (1999). La Organización de los Estados Americanos y la lucha contra la corrupción. En Comité Jurídico Interamericano, XXV Curso de Derecho Internacional - Río de Janeiro 1998 (pp. 231-254). Washington D.C.: Secretaría General de la OEA.

Mainwaring, S. y Pérez-Liñán, A. (2014). Democracies and Dictatorships in Latin America. Nueva York: Cambridge University Press.

OEA. (1984). Reuniones de Consulta de Ministros de Relaciones Exteriores. Colección de actas finales. Tomo I. Washington DC.: Secretaría General de la OEA.

Pérez-Liñán, A. (2007). Presidential Impeachement and the new political instability in Latin America. Nueva York: Cambridge University Press. https://doi.org/10.1017/ СBO9780511510335

Perret, L. (2001). Desafíos que enfrenta la formación jurídica en las Américas durante el próximo siglo. En Comité Jurídico Interamericano, XXVII Curso de Derecho Internacional, Río de Janeiro 2000 (pp. 347-355). Washington D.C.: Secretaría General de la OEA. 